\title{
A alma da arte
}

\section{The soul of art}

\author{
Carlos Alberto Augusto ${ }^{1}$
}

\begin{abstract}
Resumo
A arte e a tecnologia estiveram desde sempre ligadas. A utilização da tecnologia e das ferramentas atinge hoje um grau elevado de sofisticação. Também na arte. Isto não quer dizer que o simples uso de ferramentas e da tecnologia sofisticadas gera arte. Teremos inventado e re-inventado a roda, mas, por mais útil que ela seja, esta invenção não teria sobrevivido se não tivesse obedecido a um conjunto simples de princípios de design que lhe conferem coerência e sustentam e legitimam a longevidade do seu conceito. $\mathrm{O}$ uso da tecnologia nas artes, particularmente nas artes performativas, não está livre de obedecer às regras do design. A sua não observância pode levar à criação de produções de mérito duvidoso. A Teoria da Informação Integrada pode ajudar a perceber porquê. O exemplo do teatro da tradição ocidental, analisado à luz desta teoria, pode ajudar a ilustrar esta ideia.
\end{abstract}

\section{Palavras-chave}

Teoria da Informação Integrada; TeatroOcidental; Tecnologia; Ferramentas; Design; Consciência

\begin{abstract}
Art and technology have always been connected. Our use of tools and technologies today has attained a very high degree of sophistication. This is true in the arts. There is no guarantee however that the use of sophisticated tools and advanced technologies will generate art. We may well have invented and reinvented the wheel, and useful as it proved to be, this invention would not have lasted had it not obeyed a simple set of design principles that give it coherence and sustain and legitimise the longevity of its concept. The use of technologies in the arts, particularly in the performing arts, is not exempt from having to obey design rules. Failing to apply them may lead to a production of questionable value. Integrated Information Theory may help us understand why that is so. The example of theatre in the Western tradition, analysed under this theory, could help illustrate this.
\end{abstract}

\section{Keywords}

Integrated Information Theory; Western Theatre; Technology; Tools; Design; Consciousness.

1 Composer, sound designer, acoustic communication specialist. E-mail: info@carlosalbertoaugusto.org 


\section{Introduction}

Saint Francis of Assisi, the 12th century friar who founded the Order of Friars Minor and others, wrote about "brother Wind", "sister Moon" and "sister Water" in the Canticle of Creatures, suggesting their inherent life force and a human kinship with the elements, a common soul, if yo will. Francis Crick (1994), the neuroscientist who together with James Watson and Maurice Wilkins gave us the structure of DNA, went even further and wrote about The Astonishing Hypothesis: the scientific search for the soul. In hope of liberation but running the risk of damnation, I propose that there could be an even more astonishing hypothesis - which could be called the Sister Art hypothesis:Successful works of art possess a soul.

A soul is necessary for art to communicate itself successfully and fulfil its purpose. Isn't that what life is about?

\section{Consciousness}

We all know what consciousness is. We feel conscious, we know that others around us are conscious because of their gestures and the way they behave; language and body stance indicate they are sharing our experience. Or, on the contrary, we discover an experience that is affecting others and become ourselves conscious of it. We know what it is to lose consciousness and even if we never experience getting knocked out during a boxing tournament, we do regularly lose consciousness, albeit in a milder way on a daily basis, during certain phases of our sleep.

Consciousness is such an obvious reality that we seldom pay the necessary attention to it and yet we deal with it every day. Consciousness seems to be intertwined with the very fabric of life. Who knows, consciousness may be intertwined with everything that surrounds us.

Philosophy, science, religion and art have dealt with this subject but there seems to be no agreed upon set of rules to discuss it. Regarding consciousness, GiulioTononi (2008) noted that we know a lot about experience itself. We know 
many of the physical and physiological constraints of experience. We know a lot about which centres in the brain light up when we hear a sound, see a colour, or perceive a certain shape and which parts of the neural network fire when a certain stimulus is present. We understand many of the chemical and electro-chemical processes that occur in the brain, or at least we understand parts of these processes. Yet when we see a yellow circle, hear a tuba or smell a rose, all we can say is that we saw a yellow circle, heard a tuba or smelled a rose and that's it. Defining consciousness is difficult without falling into a circular definition.

This problem has undoubtedly unsettled many thinkers, namely the earlier mentioned Tononi, a researcher at the department of Psychiatry of the University of Wisconsin. To help analyse the problem he proposed the Integrated Information Theory (IIT), which states that consciousness is integrated information. The following ideas are based upon Tononi's theory (2008).

Being a composer and involved in the practical activities of music making, what caught my attention and drove me to learn more about IIT was the fact that it attempted to explain problematic areas, where consciousness is seemingly present but difficult to explain or confirm.

If we consider a new born child, a sleepwalker or a person with akineticmutism (a person with eyes frozen open, who cannot speak or move), are they conscious?,Tononi questions. Are animals conscious? Are they subject to the same experiences that we are? So far, these areas seemed fairly obvious, because analysing these subjects involved processes that are biologically related to our own processes and can be experimentally verified.

Another even more intriguing question that Tononi asked is: could machines be conscious? Computers, in particular, could they have a soul? The question seems perfectly legitimate since computers perform tasks that were hitherto only in the realm of human experience. Computers recognise faces, play chess, learn tasks and they often beat us in these and other more mundane or complex tasks. Are they conscious? Can a machine, any machine or some other seemingly lifeless object, be conscious? 
What are the characteristics that define life? Why do we use expressions such as "it looks alive" when we observe almost human-like behaviour in a lifeless object? What does it mean to "give life" for an actor playing a character or a pianist playing a score?

The river moves, the wind blows. Are they alive? We know that thoroughly explainable physical processes are at play but they do not entail purposeful action. Or do they? Sometimes certain objects or situations seem to indicate that a conscious process is happening.

The question is not new. Religions, both in the East and the West, have addressed the subject of consciousness and even individuals apparently less prone to mystical perambulations, philosophers and scientists such as Leibniz or William James, have suggested a continuity of consciousness across the Universe. Koch, Penrose and others argued that consciousness is a single process that binds everything across the Universe Others claim that consciousness might be a fifth state of matter (Tegmark, 2015).

It does seem that a case can be built upon the idea that consciousness may exist outside of our brains. Unlike our chronically anthropocentric view of the universe suggests and not exclusively inside the organ where we humans experience it first hand, where we receive apparent solid proof of its existence, but in fact everywhere, provided that the founding process that drives it is present.

There is a possible conclusion to be drawn from IIT, be it the case of a living organism or an object, natural or man made. According to IIT where there is integration of information, there is consciousness.

If this is true, such a theory of consciousness could perhaps qualify as the strongest candidate to become a true theory of everything.

\section{Integrated Information Theory}

IIT is a tool aimed at providing a theoretical framework for the study of consciousness that can help answer some of these and other questions. 
As stated above, it is based on the premise that consciousness equals information integration. How is this integration accomplished? It's a two way process. There is a quantitative and a qualitative dimension to consider.

Let me give you an example. It might not be mathematically accurate or physically feasible even in terms of IIT itself, but it does help to explain the idea:

Take a light bulb. You can switch it either on or off and the bulb is only capable of producing 1 bit of information, depending on your selection. If you add another light bulb and again switch each one on or off, there will be an additional 1 bit of information. Now suppose - and let's put aside the physics and engineering of this - that you turn on both lamps at once, two bits of information are produced. The possible combinations of bits are ON-ON, ON-OFF, OFF-ON and OFF-OFF. This is a most basic and crudely sketched illustration the concept. You could add more light bulbs to the system and connect them and the overall amount of information, or number possible outcomes, would be given by the formula $2^{\mathrm{N}}$, where $\mathrm{N}$ is the number of light bulbs. Moreover, things could be further complicated by creating sub-systems of light bulbs connected to other sub-systems in nested sub-systems, forming together a big super system.

This is the quantitative aspect of the integration. Integration, according to IIT, can be measured this way and has a positive value.

Now suppose that we devise a way to keep track of all possible light bulbs in a system, keep track of all possible states they could be in, keep track of all possible connections. Suppose that the system is triggered from within, establishing automatically the appropriate connections, switching on or off the appropriate light bulbs that it deems necessary according to external or internal stimuli and as part of a series of cause-effect events. That is the qualitative aspect of integration.

We would be in trouble because we would have created a conscious lighting system.

More generally, augment a light bulb with a mechanism, an element capable of responding to events, in reaction to light, to sound, to smell or in fact, any 
other factor, natural or artificially produced, real or abstract, such that it is capable of switching itself on or off as necessary. Link two, three, four, a hundred, a thousand mechanisms together. Group them in sub-systems, connect these in nested sub-systems. Keep track of how many mechanisms there are and what state they are in. Evaluate each sub-system, the whole system, the partial and global state it is in at any particular moment in time, the state it was in before and predict its state in the future. A system capable of reacting to a specific situation, triggering a specific set of mechanisms, switching on a certain group while shutting off the rest and establishing the necessary sets of connections out of all possible mechanisms and connections, creating a specific, unique response. You would have now a system capable integrating information.

This is, in my interpretation of IIT and in very rough strokes, what goes on in the brain. It stores all possible situations and responses and given certain external or internal stimuli, triggers the appropriate responses by integrating the information that reaches each appropriate mechanism, discarding those that are not necessary and linking others in order to produce consciousness, which in turn generates a specific and unique experience.

In real life different systems with different levels of integration may coexist with another prevailing system with a higher degree of integration. Simultaneously, others may fade away returning to the fore if necessary in an ever evolving, dynamic process, a process that results from the higher or lower intensity of the different processes of integration that occur at a certain moment.

This higher or lower activity can result from higher or lower levels of internal or external stimulation or from any disruption of the processes affecting the mechanisms or connections. A stroke can affect this process, for example.

It is always, as the earlier mentioned Francis Crick (1994) noted, a dynamic process. 


\section{Art and Consciousness}

Consciousness drives experience, Tononi (2008) argued. This seems logical if we consider experience to be the result of a complex neural network. But what if it is the result of a set of human made, purposefully produced, artificial elements? Computers seem to fall easily into this category but could other man made constructions, objects or even concepts, be analysed under this light?

Could an object of art be conscious? What if a theatre play was alive? Could a symphony or a film constitute a complex organism?

This could help explain a lot of subjective reactions that we have towards these objects and some of the terminology we use to describe or categorize them.

Tononi's theory $(2008 ; 2015)$ relies on studies in the neurosciences and upon the very structure of the brain. Its building blocks and its terminology are therefore derived from these areas. It seems tempting to apply the principle underlying it to less obvious areas.

If we watch the same play, movie or musical performance repeatedly, in the same venue or in different venues, on consecutive days or on occasions separated months apart, we may witness how different the performances can be. Sometimes a performance simply doesn't work, other times it goes wonderfully. Could there be a cause for these inconsistencies based upon difficulties in the integration process throughout the creation of experience?

The special capacity of humans to create and use technology is a fact. Other species are capable of developing tools, but this seems to have attained such a level in the case of our own species (for which we are also paying a heavy cost) that it could possibly be considered, or have turned into, a phylogenetic trait after years of evolution. J. D. Bernal (1972: 17) wrote: "The use of a piece of wood or a stone is first of all an extension of the human frame, limbs and sense organs together. The naked man with his hands and teeth can do a certain amount: armed with a stick and a stone he can do far more". What we should ask now is different: what are the limits of the use and development of technology? Or are there limits? 
Art and technology are closely linked. Technologies embed, format, inspire and help produce all forms of art.

Yet in the case of the arts and communication, technology should be invisible. It should be an intrinsic part of art as much as our limbs or lungs are part of our bodies. We are scarcely if ever conscious of our body parts, but we don't need that awareness to be conscious of our unique individuality, of our own individual narrative. Those body parts, together with other factors, are part of a larger 'script' that helps establish our individuality and helps generate our self-consciousness. It projects our individuality into the consciousness of others.

Ever since humans have been armed with sticks and stones, artists too have used the "latest technologies" available to produce their art. Once a new technology was introduced, a debate about its use would have most certainly occurred.

I wish to suggest here that the purpose of art is to build consciousness by designing mechanisms that can allow successive processes of integration. Therefore, technology, even when art deals with it as subject matter, has to be a tool that helps complete this integration process. It cannot be an end in itself or mere decoration.

If, following Tononi's IIT, one hypothesises that art is the design of what we might call mechanisms with specific purposes (which can be scripted for future processing or unscripted and presented directly), these mechanisms are thus able to generate integration and drive experience. Integration is content. The medium is no longer the message (4), integration is.

A painting or a sculpture contains mechanisms which can be further integrated through the interaction with the viewer. A symphony or a play is simply a guide to produce these mechanisms. They become explicit and the integration process starts, once the score is actually performed by musicians. The final integrating process occurs however, only when it is performed in front of an audience. 
These mechanisms are based on the use of technology and here may lie the problem: mechanisms introduced outside of the art itself will disrupt or problematise integration. Badly designed mechanisms, based on a poor use of technology or focusing on the technology itself, may negate integration or create spurious processes that manifest new content beyond that intended.

It is not my aim to introduce a mechanistic principle for the interpretation of art, however this disruption or difficulty in the integration process might help explain why a piece of music sounds good or bad, or sounds good one day and bad the next. A faulty integration process may ruin the soul of an artistic process. The analysis of the introduction of visual mechanisms in theatre might help illustrate this.

Western Theatre is a theatre based on text. This model was born in Greece over 2500 years ago, as we know. Texts were carefully designed to convey a certain, very specific and unique experience. The text, I want to suggest here, is a way to create a process that helps generate integration. And it does so in two ways:

Firstly, the text itself contains the basic building blocks and mechanisms that help create consciousness. It starts by defining the repertoire of all possible mechanisms, connections and possible states. Each mechanism, each character, each line of dialogue, its form, has a precise and independent role that is designed to establish connections with the other mechanisms. In doing so it switches into a certain state or maintains the previous one. This is valid for each character and for groups of characters. The process is accomplished by referring back to a previous state and by anticipating a possible future state until the final experience is revealed. The text is the connection. The characters and scenes are the precise embodiment of a particular experience.

Through its dialogues, structure, recursions, connections and timestamping the text functions not only as the creator of a sort neural network, upon which partial experience is generated, it also commences to generate a certain limited amount of integration. 
Aristotle wrote in Poetics that tragedy exists even without actors or performance. I read this as a confirmation that the text establishes the infrastructure, if you will, that makes integration possible. Drama is what makes life possible.

But there is a second stage, one which completes the process. In other words, the process can never be complete until this second stage is realised. And this is the presentation of this complex structure in front of an audience. Because it is the audience that will perform the final act of integration, without which the level of consciousness, of integrated information, will inevitably remain at a low level.

We all experienced this in reading a play. Only experience and a strong act of imagination permits full integration from a simple text. It is the audience that completes the dots of these parallel secondary processes. Tragedy becomes life, real life, on stage. In front of an audience and with the audience performing a last act of integration. The text is no longer just a map or a metaphor but becomes real life.

In theatre of the western tradition, these processes take place through sound. In Greek theatre, the theatrical ritual was based on the sound of the voice and music and was performed in front of an audience in a specially built and acoustically tuned space, the amphitheatre. The audience, with likewise specially tuned ears, was enveloped by the music and listened to the delicate intricacies of the voices of the actors, sometimes at distances of more than a hundred metres.

Audiences reacted to the information coming from the stage and from the 'orchestra' with commenting, questioning and challenging the actors. The writing had to be carefully crafted in order to maintain the conditions that guaranteed experience. Sound was the key element that sustained this process, the "electrical current" that connected the theatrical neural network. Everything else appears to have been purposefully kept to a minimum so that this process of perceiving and reacting to the information coming from the stage area was maximised. "Stage," Walcott (1976: 5-6) writes, "orchestra and auditorium, formed a single unit and so 
too did the actors, chorus and spectators, all of whom were sharing in a common act of devotion."

The text is the formula used to raise experience. It defines the charactermechanism, providing a repertoire of all its possible states and interactions. At any given moment the audience can perceive the current state of any of the mechanisms, isolated or interacting with each other. This interaction provides a certain degree of integration, i.e., sets internally an initial degree of consciousness by creating a higher level of integration than its constituent parts. It also allows the audience to anticipate possible future states, and in doing so, it leads into the final stage of integration, which closes the process and defines the success of the work in generating the highest possible level of consciousness, thus creating experience.

Integration occurred, both on stage and in the 'cavea', involving audiences, sometimes over 10,000 in number. The audience was raised in the oral tradition and accustomed to the fine intricacies of the voice through the practice of rhetoric.

The classical tradition declined throughout the Middle Ages but didn't die completely and its basic building blocks survived. Meanwhile the West was moving from a worldview based on a listening perspective to one based on a visual perspective. The classical theatrical tradition was rediscovered during the Renaissance, old traditions were re-enacted and for a while, theatre continued, basically as an oral experience. The reborn theatrical tradition in England, Italy and elsewhere maintained the fundamental traits of the classical tradition, both in the writing and the performance, but soon started reflecting the visible world. The perspective and visual framing provided by the proscenium introduced a new, surprising and previously unattended element into the theatrical universe. Scenery, perspective and visual dominance conditioned the experience. Later, lights, the distancing of the audience from stage, the use of silence and darkness, all combined to complete the process, slowly transforming the theatre from an listening centred experience into a visually conditioned one. The change must have been rapid and profound. In the 16-17th century, Hartnoll (1990: 87) reveals, Ben Jonson, the English poet and playwright, refused at a certain point to write 
more masques because, as he said, "I don't want to compete with carpenters and painters of scenery any more." The acoustical balance was definitely lost and the text, as a facilitator or creator of integration and experience, was jeopardised.

The use of visual effects is perhaps the main cause of the disruption of the integration process in theatrical performance today because it introduces a new element in the theatrical neural network that was not present in the original concept. It compromises or it even suppresses the process of integration in the context of the network of mechanisms originally created. Playwrights of the postRenaissance era had difficulty in adjusting to the introduction of visual elements in their work. Contemporary playwrights rarely specify the visual dimension of their work and if they do it is not to promote integration. The visual dimension is generally added later and left to the set designer or to the director to resolve. This contrasts with cinema for example, which developed a grammar that includes this dimension as a mechanism apt to contribute to the integration process. Dramatic writing today still reflects an almost lost orality and often fails to handle the visual dimension properly, a dimension which was present perhaps only in the short lived commedia dell'arte.

In brief, if the theatrical text is presented in front of an audience who performs the final integration, it should generate information that is greater and above its constituent parts. The experience of the audience should always be greater than that generated on stage.

Any disturbance in this process, such as one that modifies the presentation of the mechanisms or prevents the final process of integration, jeopardises its completion. If all goes well however and the process of final integration generates more information than the sum of its parts, integration will achieve a high value of consciousness and therefore experience. If not, the value of consciousness will be low and only poorly defined, scattered experiences or no experience at all, will occur.

High consciousness could be a measure of the comprehension of a work of art. It is a precise concept that could perhaps replace imprecise or often poorly 
articulated and imprecise notions such as aura or catharsis. These could be considered reciprocal concepts that have been applied to the arts, but ones that originated and evolved in contexts that are detached from our present today experience.

It seems tempting to also extend these principles to other art forms, particularly those that rely on a performed text, in which a map is unfolded in front of an audience eliciting an interaction (integration) with it. Other forms of art, namely the visual arts, painting, sculpture, etc., in fact all forms of art, may also be subject to the same process but this remains to be seen.

The principles applied to theatre can also be applied to music or cinema. A text, a script, a score, have the same purpose.

The process in cinema is quite similar to the one in theatre, except that it incorporates the visual elements and conceives them as mechanisms. Cinema, unlike theatre, incorporates a visual grammar. Theatre never seems to have managed to do this successfully, except perhaps, as mentioned above, in the case of commedia dell'arte.

\section{Conclusion}

Art, as I have suggested, can be seen as the creation of mechanisms that combine with each other in order to produce experience. If we follow the IIT principles, this means that the product that results from this combination is an artificial object which has consciousness; art that has a soul. The nature of the mechanisms produced in different art forms varies. The nature of the processes of integration derived from the interaction of these mechanisms however, can be compared to the processes that go on at the level of neural networks and, still under the light of IIT, seems to produce an experience similar to what we call consciousness. Questioning the possibility of generating experience through the creation of artificial mechanisms thus seems as futile as questioning the possibility, which we now deem real, that a computer can generate experience, that is possess consciousness. 
Some art forms are based on simple mechanisms that are not mediated in a complex way. Integration is simple and direct. Literature or the traditional fine arts are examples of this. Full integration is accomplished by the reader or viewer, simply at the reading stage. Other art forms generate more complex mechanisms and yet others still, actual physical sub-mechanisms that go through a much more complex process of integration, for example the performing arts and cinema. These art forms are also based on much more complex technological systems. Final integration goes through several stages and through a set of complex conditions.

It is nevertheless always a dynamic process. The possibility of full interaction and the generation of experience can be facilitated or disturbed as in any other system. Some processes can be in the foreground, others in the background and all may surface at a certain point. Integration happening in the foreground can be disturbed by the sudden appearance of extraneous mechanisms and the integration processes that they themselves generate.

In art, mechanisms are artificially produced and have to be carefully designed in order to entail integration. Poorly conceived mechanisms, and unexpected or extraneous ones can disturb or destroy the integration processes. Design flaws or extraneous, unforeseen mechanisms will change, trouble or totally disrupt the possibility of generating experience.

Humankind evolved and survived with the help of sticks and stones. New tools and more sophisticated technologies helped further the evolution of our species.

Technology is as essential today as it was during our very beginnings. Art is inconceivable without technology however is situated above it, as much as consciousness is above its neural correlates.

\section{References}

ARISTÓTELES. Poética. Trad. Ana Maria Valente.Lisboa: Fundação CalousteGulbenkian, 2004. 
VIS

Revista do Programa de Pós-graduação em Arte da UnB

ARNOTT, Peter D. Public Performance in the Greek Theatre. New York: Routledge, 1989.

BENNETT, Susan. Theatre Audiences. New York: Routledge, 1990.

BERNAL, John Desmond.The Extension of Man: a History of Physics Before 1900. Londo: Paladin, 1972.

CRICK, Francis. The Astonishing Hypothesis: The Scientific Search for the Soul. New York: Touchstone, 1994.

HARTNOLL, Phyllis. The Theatre, A Concise History. London, Thames \& Hudson, 1987.

McLUHAN, Marshall. Understanding Media: the Extensions of Man. London: Abacus, 1973.

TEGMARK, Max. Consciousness as a State of Matter.Chaos, Solitons\& Fractals, vol. 76, 238-270, 2018.

TONONI, Giulio. Consciousness as Integrated Information: a Provisional Manifesto. The Biological Bulletin, 215: 218-242. Chicago: The University of Chicago Press Books, 2008.

TONONI, Giulio; KOCH, Christof. Consciousness: here, there and everywhere?.Philosophical Transactions of the Royal Society B - Volume 370, issue 1668. London: The Royal Society Publishing, 2015.

WALCOTT, Peter. Greek Drama in its Theatrical and Social Context. Cardiff: University of Wales Press, 1976. 